Int. J. Electrochem. Sci., 13 (2018) $6522-6536$

\title{
Synergistic Inhibition Effect of Sodium Tungstate and Zinc Sulphate on Mild Steel Corrosion in Seawater
}

\author{
Jinliang Zhang ${ }^{1,2}$, Lijing Zhang ${ }^{1, *}$, Gang Tao ${ }^{1}$, Fangying Cui $^{3}$ \\ ${ }^{1}$ College of Safety Science and Engineering, Nanjing Tech University, Nanjing 210009, China \\ ${ }^{2}$ School of Materials and Chemical Engineering, Ningbo University of Technology, Ningbo 315211, \\ China \\ ${ }^{3}$ School of Chemistry and Chemical Engineering, Chongqing University, Chongqing 400044, China \\ *E-mail: zhanglj_njtech@163.com
}

doi: $10.20 .964 / 2018.07 .50$

Received: 8 March 2018 / Accepted: 3 May 2018 / Published: 5 June 2018

The desirable concentrations of sodium tungstate (ST) along with zinc sulfate (ZS) were selected for mild steel in seawater, and the inhibition effect of ST and ZS under wet/dry cyclic condition was investigated using weight loss and electrochemical methods. Results showed that the inhibition efficiency could reach $84.81 \%$ after $10 \mathrm{wet} /$ dry cycles. Corrosion products were observed and analyzed by scanning electron microscopy (SEM) and X-ray diffraction (XRD). Corrosion behaviours under different wet/dry ratios were studied, which showed that the longer drying time was, the more serious corrosion was. The inhibition mechanism was that $\mathrm{Fe}_{2} \mathrm{WO}_{6}$ attached to the steel surface and retarded the corrosion reaction.

Keywords: Corrosion inhibition; Synergistic effect; Mild steel; EIS; Weight loss.

\section{$\underline{\text { FULL TEXT }}$}

(C) 2018 The Authors. Published by ESG (www.electrochemsci.org). This article is an open access article distributed under the terms and conditions of the Creative Commons Attribution license (http://creativecommons.org/licenses/by/4.0/). 